\begin{tabular}{ll|l} 
Case Reports in & \multicolumn{2}{c}{ Case Rep Gastroenterol 2013;7:314-321 } \\
\cline { 2 - 3 } Gastroenterology & $\begin{array}{l}\text { DOI: } 10.1159 / 000354276 \\
\text { Published online: July 23, 2013 }\end{array}$ & $\begin{array}{l}\text { ○ 2013 S. Karger AG, Basel } \\
1662-0631 / 13 / 0072-0314 \$ 38.00 / 0 \\
\text { www.karger.com/crg }\end{array}$ \\
\hline & $\begin{array}{l}\text { This is an Open Access article licensed under the terms of the Creative Commons Attribution- } \\
\text { NonCommercial-NoDerivs 3.0 License (www.karger.com/OA-license), applicable to the } \\
\text { online version of the article only. Distribution for non-commercial purposes only. }\end{array}$
\end{tabular}

\title{
Severe Acute Pancreatitis with Complicating Colonic Fistula Successfully Closed Using the Over-the-Scope Clip System
}

\author{
Ken Ito Yoshinori Igarashi Takahiko Mimura Yui Kishimoto \\ Itaru Kamata Shunsuke Kobayashi Kensuke Yoshimoto Naoki Okano \\ Division of Gastroenterology and Hepatology, Toho University Omori Medical Center, \\ Tokyo, Japan
}

\section{Key Words}

Colonic fistula $\cdot$ Endoscopic treatment $\cdot$ Pancreatic duct disruption $\cdot$ Severe acute pancreatitis

\begin{abstract}
A 44-year-old man presenting to our hospital emergency room with abdominal pain was hospitalized for hyperlipidemic acute pancreatitis. A pig-tail catheter was placed percutaneously to drain an abscess on day 22. Although the abscess improved gradually and good clinical progress was seen, pancreatic duct disruption was strongly suspected and endoscopic retrograde cholangiopancreatography was performed on day 90. An endoscopic nasopancreatic drainage tube was placed, but even with concurrent use of a somatostatin analogue, treatment was ineffective. Surgical treatment was elected, but was subsequently postponed as the abscess culture was positive for extended-spectrum $\beta$-lactamase-producing Escherichia coli and methicillin-resistant Staphylococcus aureus. Drainage tubography showed a small fistula of the colon at the splenic flexure on day 140. Colonoscopy was performed on day 148. After indigo carmine had been injected, a fistula into the splenic flexure of the colon showed blue staining. The over-the-scope clip (OTSC) system was used to seal the fistula and complete closure was shown. A liquid diet was started on day 159 and was smoothly upgraded to a full diet. Following removal of the pancreatic stent on day 180, drainage volume immediately decreased and the percutaneous drain was removed. On day 189, computed tomography showed no exacerbation of the abscess and the patient was discharged on day 194. This case of colonic fistula caused by severe acute pancreatitis was successfully treated using the OTSC system, avoiding the need for an open procedure.
\end{abstract}




\section{Introduction}

Acute pancreatitis is an acute inflammatory process of the pancreas that may involve peripancreatic tissues or remote organ systems, and occasionally pancreatic complications, such as pancreatic abscess and pancreatic duct disruption, and colonic complications may occur [1]. In recent years, endoscopic treatment has proven to be an effective alternative to surgical techniques for pancreatic duct disruption [2]. Currently, the standard treatment for colonic perforation is open surgical repair. Application of conventional endoclips has been reported with satisfactory clinical outcomes in some cases, but seems to be limited to small, localized lesions. Therefore, more sophisticated closure techniques are desirable.

Here we report a case in whom colonic fistula due to severe acute pancreatitis was treated endoscopically using the over-the-scope clip system (OTSC system; Ovesco Endoscopy AG, Tübingen, Germany), and as a result, pancreatic duct disruption was treated without the need for endoscopic treatment.

\section{Case Report}

A 44-year-old man presented to the emergency room with continuous abdominal pain and met the diagnostic criteria for systemic inflammatory response syndrome $\left(39^{\circ} \mathrm{C}\right.$, 130 beats/min, 20 breaths/min). Laboratory tests showed elevation of leukocyte count (WBC) and levels of C-reactive protein (CRP), transaminase, amylase, pancreatic amylase and triglyceride (table 1). Two of Ranson's criteria were positive (WBC $>16,000$ cells $/ \mathrm{mm}^{3}$; blood glucose $>200 \mathrm{mg} / \mathrm{dl}$ ) [3]. Contrast-enhanced computed tomography (CT) revealed necrotizing pancreatitis and a diagnosis of hyperlipidemic acute pancreatitis was made. Although extrapancreatic progression of inflammation extended to the anterior pararenal space, there were hypoenhanced lesions in two segments of the pancreas.

Conservative treatment including high-volume infusion, prophylactic antibiotic (meropenem), protease inhibitors and intravenous immune globulin were started immediately. Follow-up CT revealed massive peripancreatic fluid collection and an abscess in the left abdominal cavity (fig. 1). CT-guided percutaneous drainage was performed for the pancreatic abscess. No improvement was seen and a 7-Fr pig-tail drainage catheter was placed on hospital day 22. Abscess culture was positive for extended-spectrum $\beta$-lactamase (ESBL)producing Escherichia coli and methicillin-resistant Staphylococcus aureus (MRSA). The cavity was lavaged of debris and purulent material.

A 12-Fr silicon catheter was subsequently placed on day 34, 8-Fr and 7-Fr pig-tail catheters were placed on day 48, and the catheter was dilated gradually. Immediately after irrigation of a temporary drain, high fever developed, so we switched to continuous drainage. A 16-Fr drainage catheter inserted on day 69 achieved good drainage. Maroon-colored fluid from the abscess drainage changed to clear fluid on day 78. The volume of fluid drained did not decrease, however, and remained between 200 and $400 \mathrm{ml}$ per day. The fluid was high in amylase and as pancreatic duct disruption was strongly suspected, endoscopic retrograde cholangiopancreatography (ERCP) was performed on day 90. The results showed disruption on the tail of the main pancreatic duct with contrast extravasation. An endoscopic nasopancreatic drainage (ENPD) tube was therefore placed at the tail. With the aim of achieving fistula closure and reduction of output, octreotide ( $300 \mu \mathrm{g} /$ day) was used concurrently.

As the volume of fluid drained did not decrease below $50 \mathrm{ml} /$ day, octreotide was increased to $600 \mu \mathrm{g} /$ day on day 105 . To increase drainage volume, a 7-Fr pancreatic stent was placed endoscopically on day 111 and dilated to $8.5 \mathrm{Fr}$ on day 133. Fluid volume de- 
Ito et al.: Severe Acute Pancreatitis with Complicating Colonic Fistula Successfully Closed Using the Over-the-Scope Clip System

creased for around 2 weeks but thereafter increased gradually, so we discontinued octreotide on day 130 . We had reached the limit of conservative management at this point and explored the indications for surgical therapy. However, as the abscess culture was still positive for ESBL-producing E. coli and MRSA, surgical treatment was postponed. CRP and WBC were stable and the patient had no abdominal complaint, so a liquid diet was started on day 138. The patient ran a fever $>38^{\circ} \mathrm{C}$ the following day, diet was stopped and radiography was performed on day 140 for pyrexia. Drainage tubography showed a small fistula of the colon at the splenic flexure (fig. 2); the diagnosis was thus amended to colonic fistula complicated by severe acute pancreatitis. Drainage was effective and therefore the cause of the colonic fistula was suspected to be protraction of the pancreatic fistula.

To investigate the communication of fistulas, colonoscopy was performed (CF H-260 AI; working channel of $3.7 \mathrm{~mm}$; Olympus Medical Systems, Tokyo, Japan). After indigo carmine injection, the fistula into the splenic flexure of the colon showed blue staining (fig. 3a, b). The fistula was a small erosion and endoscopic treatment appeared feasible. An attempt to seal the perforation endoscopically was performed using the OTSC system (fig. 3c). Once the colonoscope had been removed, the OTSC applicator was mounted on the tip of the endoscope and reinserted. The tissue edges, including the fistula, were gently pulled inside the cap while continuous suction was applied. The OTSC clip (type T, $10 \mathrm{~mm}$ diameter) was released and the fistula was sealed. A Gastrografin enema performed on day 151 showed complete sealing of the leak and improved clinical course.

A liquid diet was restarted after ENPD tube exchange on day 159 and was smoothly upgraded to a full diet. However, a 7-Fr endoscopic pancreatic stent (EPS) was placed for internal drainage on day 175 because of an increase in the volume of percutaneous drainage. After removing the EPS on day 180, drainage volume immediately decreased. CT on day 189 showed no exacerbation of the abscess and the patient was discharged on day 194.

Follow-up CT and colonoscopy of the pancreatic and colonic fistulas were performed on day 221. CT showed improvement of the abscess, colonoscopy indicated the clip was in situ and scarred and the perforation site was sealed with no signs of inflammation or ulceration. ERCP performed on day 223 revealed no pancreatic duct disruption. The patient's clinical course was good and he is now receiving outpatient therapy for hyperlipidemia.

\section{Discussion}

Acute pancreatitis is defined as an acute inflammatory process of the pancreas that may involve peripancreatic tissues or remote organ systems. Severe acute pancreatitis is characterized by systemic organ failure as well as local pancreatic complications, and is associated with a mortality rate of $15-30 \%$, despite continuing improvements in critical care [4]. Although pancreatic complications such as pancreatic abscess occasionally occur, of the many patients with severe acute pancreatitis, colonic complications affect only $1 \%$ [5]. Necrotizing pancreatitis develops in $10-20 \%$ of patients with acute pancreatitis and the mortality is unfavorable, reaching $15-20 \%$. The prognosis after complications of organ failure or infections with necrotizing pancreatitis is worse still [6].

Liquid pus collection is the main lesion in most patients with pancreatic abscess, and it has been reported recently that $78-86 \%$ of the patients can be cured by percutaneous drainage alone [7]. In severe necrotizing pancreatitis, liquefactive necrosis may occur, leading to pancreatic necrosis. Associated pancreatic duct disruption may persist as a fistula and result in persistent fluid collection or may heal spontaneously. 
Ito et al.: Severe Acute Pancreatitis with Complicating Colonic Fistula Successfully Closed Using the Over-the-Scope Clip System

In the present case, at the point where pancreatic duct disruption at the pancreatic duct tail was suspected from the high amylase level in abscess drainage, we immediately attempted endoscopic drainage by placing an ENPD tube and pancreatic stent. Unfortunately, the output did not decrease despite coadministration of octreotide, and we could not achieve a therapeutic effect.

Pancreatic juice levels from the drain did not decrease after sealing the colonic fistula, in spite of removal of the ENPD tube being in favor of an EPS. The fistula was located at the pancreatic tail and the end of the EPS was just proximal to it. To solve this problem, we removed the EPS and thereafter pancreatic juice fluid volume decreased. This was assumed to be due to improvement of the pancreatic duct disruption, so we were then able to remove the abscess drain. Thus, the volume from the external drain was useful as an indicator of main pancreatic duct disruption with retroperitoneal abscess (or pseudocyst).

In treating patients who have undergone necrostomy, we believe amylase levels in drainage fluid should be monitored. When the drain output and the fluid amylase concentration are high, the drains should not be continued if soft feeding tubes are introduced. In such patients, pancreatic ductal anatomy should be studied with ERCP and a fistulogram should be made to assess the ductal anatomy proximal and distal to the fistula in planning an appropriate surgery [8].

The success of somatostatin analogues such as octreotide in attempts to control and promote closure of such fistulas will depend on the extent of the initial injury. When necrosis has affected several centimeters of the duct along with the surrounding pancreatic parenchyma, closure is seldom achieved because the anatomic abnormality remains uncorrected. Conservative management of pancreatic fistula consists of adequate drainage, fluid balance correction and nutritional support. This leads to spontaneous closure in up to $80 \%$ of patients, although this may take up to 6 months [9]. The use of somatostatin analogues for the management of fistulas is widely recognized [10] and they are used for the conservative management of pancreatic fistula with the aim of achieving fistula closure or reduction of output. Although we started a somatostatin analogue early, we lost the effect with prolonged use and could not achieve a cure. Gans et al. [11] reported that there was no solid evidence that somatostatin analogues result in a higher closure rate of pancreatic fistula compared with other treatments. So in cases like this, we should not use somatostatin analogues for pancreatic duct disruption, but instead emphasize the importance of treatment for the primary disease.

Colonic complications of acute pancreatitis are quite rare, are difficult to identify and treat, and therefore are associated with high morbidity and mortality. Colonic fistula development depends on two factors: extension of pancreatic necrosis into the mesocolon with encasing pericolic fibrosis, and parietal ischemic necrosis secondary to shock and thrombosis with infection. They are managed with surgical closure, bowel rest, antibiotics and nutritional support, with surgery remaining the mainstay of treatment for such patients [12]. Endoscopic fistula repair could be an effective and less invasive modality in the management of these patients and may obviate the need for surgical intervention in a proportion of them. Conventional endoclips are currently used to close small perforations with favorable outcomes, but they may not be sufficient to safely close perforations $>10 \mathrm{~mm}$ [13]. Only a few experiences have been reported in the literature describing closure of perforation of a colon fistula caused by severe acute pancreatitis using endoscopic clipping devices [14].

The OTSC system is a new method for the mechanical compression of tissue in the gastrointestinal tract and was first reported by Kirschniak et al. in 2007 [15]. The clip consists of a nitinol alloy, which allows a high grade of elasticity. It is installed onto the applicator in a bent state. When released from the applicator, the shape-memory effect and the high grade 
Ito et al.: Severe Acute Pancreatitis with Complicating Colonic Fistula Successfully Closed Using the Over-the-Scope Clip System

of elasticity of the nitinol alloy cause closure of the clip. Because of the superelastic effect of nitinol, the force is permanently applied. The OTSC system complements the products that are currently available and gives endoscopists a tool for the immediate management of complications such as deep-walled lesions, perforations and difficult bleeding. In the present case, the successful outcome depended on four points: (i) immediate diagnosis of the colonic fistula, (ii) tight closure of the colonic fistula using the OTSC system, (iii) sufficient drainage and closed lavage of the pancreatic area, and (iv) adequate timing of EPS removal using the percutaneous drainage volume.

To our knowledge there are no reports of colonic fistula in patients with severe acute pancreatitis who were treated in Japan with an endoscopic closure mechanism such as a clipping device. Fistula closure using the OTSC system represents a promising sphincterpreserving minimally invasive procedure. In our patient, clip application was safe and effective, without early or late complications. The OTSC system may represent a new therapeutic option in the management of postoperative colonic fistula. Moreover, abscess ERCP should be carried out whenever main pancreatic duct disruption is suspected.

\section{References}

1 Banks PA, Freeman ML; Practice Parameters Committee of the American College of Gastroenterology: Practice guidelines in acute pancreatitis. Am J Gastroenterol 2006;101:2379-2400.

-2 Rana SS, Bhasin DK, Nanda M, et al: Endoscopic transpapillary drainage for external fistulas developing after surgical or radiological pancreatic interventions. J Gastroenterol Hepatol 2010;25:1087-1092.

3 Ranson JHC: Acute pancreatitis: surgical management; in Go VLW, Dimango EP, Gardner JD, Lebenthal E, Reber HA, Scheele GA (eds): The Pancreas: Biology, Pathobiology and Disease, ed 2. New York, Raven, 1993, pp 637-648.

4 Gloor B, Müller CA, Worni M, et al: Late mortality in patients with severe acute pancreatitis. Br J Surg 2001;88:975-979.

5 Abrican H, Eftaiha M, Kraft AR, et al: Colonic complications of acute pancreatitis. Arch Surg 1979;114: 995-1001.

6 Takeda K, Yamauchi J, Shibuya K, et al: Benefit of continuous regional arterial infusion of protease inhibitor and antibiotic in the management of acute necrotizing pancreatitis. Pancreatology 2001;1:668-673.

7 Baril NB, Ralls PW, Wren SM, et al: Does an infected peripancreatic fluid collection or abscess mandate operation? Ann Surg 2000;231:361-367.

-8 Ho HS, Frey CF: Gastrointestinal and pancreatic complications associated with severe pancreatitis. Arch Surg 1995;130:817-822; discussion 822-823.

-9 Gayral F, Campion JP, Regimbeau JM, et al; Lanreotide Digestive Fistula: Randomized, placebo-controlled, double-blind study of the efficacy of lanreotide $30 \mathrm{mg}$ PR in the treatment of pancreatic and enterocutaneous fistulae. Ann Surg 2009;250:872-877.

-10 Hesse U, Ysebaert D, de Hemptinne B: Role of somatostatin-14 and its analogues in the management of gastrointestinal fistulae; clinical data. Gut 2001;49(suppl 4):iv11-iv21.

11 Gans SL, van Westreenen HL, Kiewiet JJS, et al: Systematic review and meta-analysis of somatostatin analogues for the treatment of pancreatic fistula. Br J Surg 2012;99:754-760.

12 Gardner A, Gardner G, Feller E: Severe colonic complications of pancreatic disease. J Clin Gastroenterol 2003;37:258-262.

13 von Renteln D, Schmidt A, Vassiliou MC, et al: Endoscopic closure of large colonic perforations using an over-the-scope clip: a randomized controlled porcine study. Endoscopy 2009;41:481-486.

14 Familiari P, Marci A, Consola P, et al: Endoscopic clipping of a colocutaneous fistula following necrotizing pancreatitis: case report. Dig Liver Dis 2003;35:907-910.

15 Kirschniak A, Kratt T, Stuker D, et al: A new endoscopic over-the-scope clip system for treatment of lesions and bleeding in the GI tract: first clinical experiences. Gastrointest Endosc 2007;66:162-167. 


\section{Case Reports in
Gastroenterology}

\begin{tabular}{l|l}
\hline Case Rep Gastroenterol 2013;7:314-321 \\
\hline DOI: 10.1159/000354276 & $\begin{array}{l}\text { @ } 2013 \text { S. Karger AG, Basel } \\
\text { www.karger.com/crg }\end{array}$
\end{tabular}

Ito et al.: Severe Acute Pancreatitis with Complicating Colonic Fistula Successfully

Closed Using the Over-the-Scope Clip System

Table 1. Laboratory data

\begin{tabular}{ll}
\hline $\mathrm{WBC}, \times 10^{3} / \mu \mathrm{l}$ & 23.3 \\
$\mathrm{RBC}, \times 10^{6} / \mu \mathrm{l}$ & 5.55 \\
$\mathrm{Hb}, \mathrm{g} / \mathrm{dl}$ & 22.3 \\
$\mathrm{Hct}, \%$ & 49.8 \\
$\mathrm{MCV}, \mathrm{fl}$ & 89.6 \\
$\mathrm{MCH}, \%$ & 40.2 \\
$\mathrm{Plt}, \times 10^{3} / \mu \mathrm{l}$ & 282 \\
$\mathrm{BGA}$ & \\
$\quad \mathrm{pH}$ & 7.39 \\
$\quad \mathrm{PCO}_{2}, \mathrm{~mm} \mathrm{Hg}$ & 29.4 \\
$\quad \mathrm{PO}_{2}, \mathrm{~mm} \mathrm{Hg}$ & 64.0 \\
$\quad \mathrm{HCO}, \mathrm{mmol} / \mathrm{l}$ & 17.5 \\
$\mathrm{BE}$ & -5.5 \\
$\mathrm{TP}, \mathrm{g} / \mathrm{dl}$ & 7.8 \\
$\mathrm{Alb}, \mathrm{g} / \mathrm{dl}$ & 4.5 \\
$\mathrm{~T}-\mathrm{Bil}, \mathrm{mg} / \mathrm{dl}$ & 0.7 \\
$\mathrm{D}-\mathrm{Bil}, \mathrm{mg} / \mathrm{dl}$ & 0.2 \\
$\mathrm{AST}, \mathrm{IU} / \mathrm{l}$ & 35 \\
$\mathrm{ALT}, \mathrm{IU} / \mathrm{l}$ & 30 \\
$\mathrm{LDH}, \mathrm{IU} / \mathrm{l}$ & 268 \\
$\mathrm{ALP}, \mathrm{IU} / \mathrm{l}$ & 491 \\
$\gamma \mathrm{GTP}, \mathrm{IU} / \mathrm{l}$ & 591 \\
$\mathrm{~T}-\mathrm{Cho}, \mathrm{mg} / \mathrm{dl}$ & 523 \\
$\mathrm{TG}, \mathrm{mg} / \mathrm{dl}$ & 5,547 \\
$\mathrm{BUN}, \mathrm{mg} / \mathrm{dl}$ & 15 \\
$\mathrm{Cr}, \mathrm{mg} / \mathrm{dl}$ & 1.1 \\
$\mathrm{Na}, \mathrm{mM}$ & 127 \\
$\mathrm{~K}, \mathrm{mM}$ & 4.0 \\
$\mathrm{Cl}, \mathrm{mM}$ & 95 \\
$\mathrm{Ca}, \mathrm{mg} / \mathrm{dl}$ & 8.3 \\
$\mathrm{AMY}, \mathrm{IU} / \mathrm{l}$ & 675 \\
$\mathrm{PAMY}, \mathrm{IU} / \mathrm{l}$ & 643 \\
$\mathrm{CK}, \mathrm{IU} / \mathrm{l}$ & 34 \\
$\mathrm{BS}, \mathrm{mg} / \mathrm{dl}$ & 294 \\
$\mathrm{CRP}, \mathrm{mg} / \mathrm{dl}$ & 5.8 \\
\hline & \\
& \\
\hline
\end{tabular}




\section{Case Reports in \\ Gastroenterology}
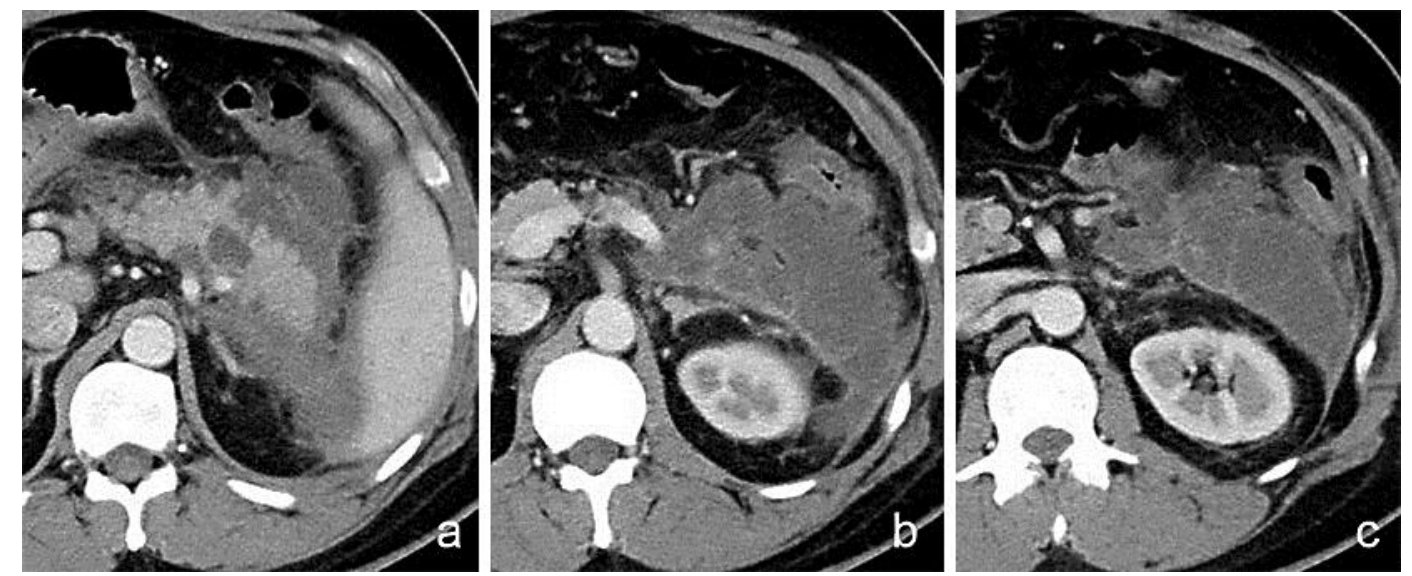

Fig. 1. a-c Abdominal CT showing exacerbation of the peripancreatic fluid collection and abscess.

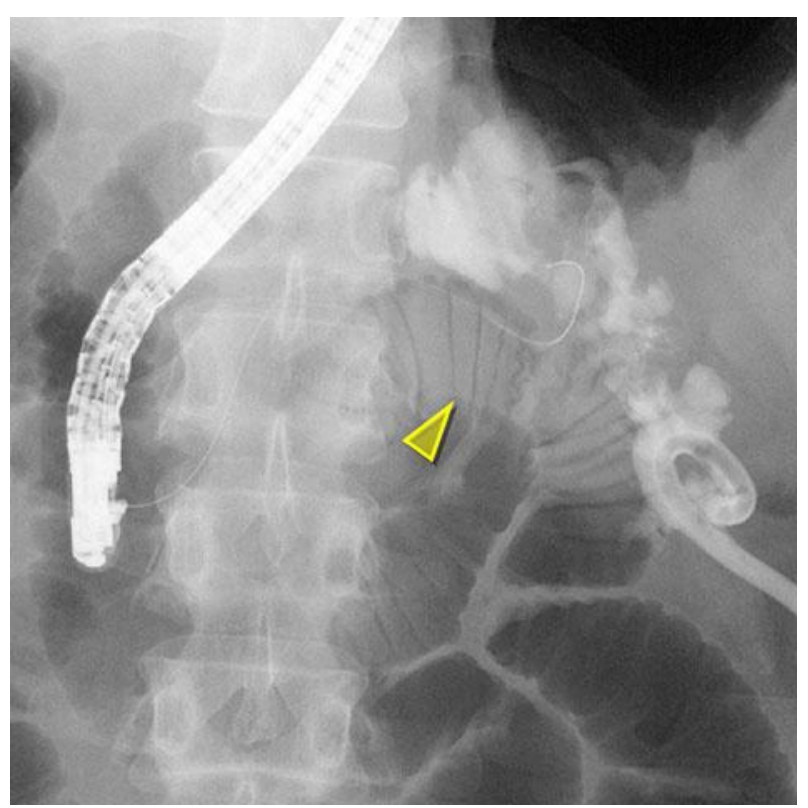

Fig. 2. Drainage tubography showed a fistula of the colon at the splenic flexure (arrowhead). 

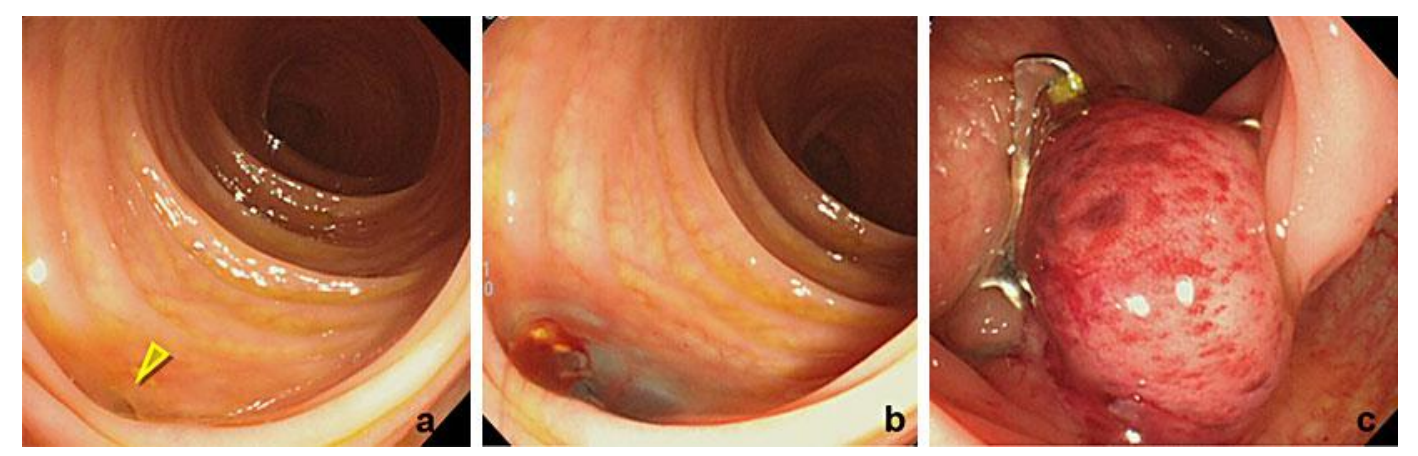

Fig. 3. The fistula into the splenic flexure was a small erosion (a) that stained blue after indigo carmine injection (b). The OTSC clip was released and sealed the fistula (c). 